\title{
Electronic Nose as a Tool for Monitoring the Authenticity of Food. A Review
}

\author{
Anna Gliszczyńska-Świgło ${ }^{1}$. Jarosław Chmielewski ${ }^{1}$
}

Received: 22 July 2016 / Accepted: 28 November 2016 / Published online: 6 December 2016

(C) The Author(s) 2016. This article is published with open access at Springerlink.com

\begin{abstract}
Counterfeiting of food is recently one of the risks relevant for producers, distributors, retailers, consumers, and national governments from economic (price), health (allergens), and religious reasons. Flavour of several food products is one of the key attributes of their quality and authenticity. In the case of some foods, the aroma of a product is specific enough to discriminate an original product from its fraud or adulterated counterpart. Electronic nose (e-nose) is a rapid and powerful technique, which requires no special sample preparation to determine the aroma of a product. In the present review, the applications of different e-noses and chemometrics for determination of food authenticity including adulteration and confirmation of origin are discussed. E-noses of various configurations are a very promising tool for testing the authenticity of food products.
\end{abstract}

Keywords Food authenticity · Food adulteration · Origin confirmation $\cdot$ Food aroma $\cdot$ Electronic nose $\cdot$ Chemometrics

\section{Introduction}

Counterfeiting of food is one of the risks gaining recently more and more attention from producers, distributors, retailers, consumers, and national governments (Moore et al. 2012). In May 2009, the Food and Drug Administration (FDA) created the term economically motivated adulteration

Anna Gliszczyńska-Świgło

a.gliszczynska-swiglo@ue.poznan.pl; anna.gliszczynskaswiglo@ue.poznan.pl

1 Faculty of Commodity Science, Poznań University of Economics and Business, al. Niepodległości 10, 61-875 Poznań, Poland
(EMA) as a subcategory of food fraud. It was defined as “... the fraudulent, intentional substitution or addition of a substance in a product for the purpose of increasing the apparent value of the product or reducing the cost of its production (...). EMA includes dilution of products with increased quantities of an already-present substance to the extent that such dilution poses a known or possible health risk to consumers, as well as the addition or substitution of substances in order to mask dilution" (Spink and Moyer 2011).

Maximization of commercial profit is usually behind counterfeiting of food. Authenticity of food covers such aspects as adulteration, false or misleading origin or characterization of the product, and its mislabelling. The most common fraudulent procedure is partial or complete substitution of an authentic ingredient or material with a cheaper and easily available component (Hrbek et al. 2014). It leads to worse quality product usually without a substantial effect on human health. In the last years, however, the incidences of food fraud or adulteration seriously dangerous to human health took place. The most known examples are the following: (1) a mass poisoning of Chinese children in 2008 caused by melamine added to milk to overestimate the protein content in this product, and (2) methanol poisoning occurred in 2012 in the Czech Republic, Poland, and Slovakia due to adulteration of "on tap" liquor of unknown origin. The information on this incident was distributed through the Rapid Alert System for Food and Feed (RASFF) by the Czech Republic (RASFF Annual Report 2012).

The authenticity of various products, e.g. honey, wine, some dairy or meat products, is sometimes associated with a geographical area of production and/or specific processing technology. Symbols of Protected Geographical Indication (PGI), Protected Designation of Origin (PDO), and Traditional Speciality Guaranteed (TSG) have been created and introduced by the European Union (EU) to protect 
specific regional foods from misuse and imitation. Verification of producers declaring the originality of PDO, PGI, and TSG products is also important for consumers.

There are a lot of adulterants that could be found in food. Several methods are used to evaluate the quality or detect adulteration in food. Some of them give information about the composition of the native constituents or of the appearance of a possible adulterant. They comprise chemical and chromatographic methods as well as spectroscopic techniques, such as mass spectrometry (MS), ultraviolet-visible (UVVis) spectroscopy, Fourier transform near infrared (FT-NIR) spectroscopy, Fourier transform infrared (FT-IR) spectroscopy, Raman spectroscopy, nuclear magnetic resonance (NMR) spectroscopy, and fluorescence spectroscopy. In combination with chemometrics, they became powerful tools for quality control or determination of authenticity of food (Chou et al. 2007; Coppa et al. 2012; Cozzolino and Murray 2004; Kamal and Karoui 2015; Krist et al. 2006; Lohumi et al. 2015; LópezDíez et al. 2003; Lv et al. 2014; Meza-Marquez et al. 2010; Mohammed et al. 2013; Poulli et al. 2007; Rohman et al. 2011; Salguero-Chaparro et al. 2013; Šmejkalová and Piccolo 2010; Stanimirova et al. 2010; Tu et al. 2014; Zhang et al. 2008; reviewed also in e.g. Reid et al. 2006). The techniques used for the detection of some food adulterants include also molecular biology-based and enzyme-linked methods (Asensio et al. 2008; Chen et al. 2010; Ghovvati et al. 2009). Although these methods are usually the most specific and sensitive, they require expensive equipment and highdegree technical expertise. They also have higher falsepositive rates (Tian et al. 2013).

All aforementioned analytical techniques, excluding gas chromatography (GC), cannot be used for the determination of volatile compounds. Flavour of several food products is one of the key attribute of their quality. The volatile compounds of foods are diverse and originate from raw materials and/or are generated during production, maturation, and storage. Unique volatile compounds may characterize some products, and such aroma markers could be identified to confirm their authenticity (Pillonel et al. 2003). However, determination of the changes in the composition of food volatile compounds due to counterfeiting procedure may be sometimes insufficient to confirm the authenticity of a product. Moreover, extraction, separation, and identification of compounds, considered as markers of fraud or authentic food, using chromatographic methods are usually labour- and time-consuming. Therefore, the application of tool for real-time, rapid, and effective determination of the authenticity of a product based on its aroma is important for fast detection of adulterant.

Electronic noses (e-noses) are devices used for analysing food aroma generally without separation and identification of volatile compounds. A typical e-nose comprises (1) the sampling system, (2) a set of non-selective sensors or a mass spectrometer (MS), or their combination as a collecting unit, and (3) a data acquisition system for signal processing and software with multivariate data processing tools to recognize and classify products according to their specific odour (pattern recognition system) (Dymerski et al. 2011). Chemical sensors or MS in e-noses are the most important part of the system because they provide information about measured parameters (Śliwińska et al. 2014). The most frequently used sensors of enoses are electrochemical (amperometric and conductometric), piezoelectric, and optical (smell-sensing), and those based on GC and MS (Dymerski et al. 2011; Śliwińska et al. 2014). The number and type of sensors as well as their selectivity and sensitivity depend on the e-nose application. Enoses, due to their rapid screening capacity, are a promising alternative to GC, which admittedly gives information about the volatile composition of food, but is rather expensive and time-consuming. Some of the advantages of e-nose are its simplicity or no special sample preparation, relatively short analysis time, and low cost of analysis per sample. E-noses of different configurations are successfully used for aroma characterization of various food products such as oils, meat, fish, alcoholic and non-alcoholic beverages, honeys, fruits, and other products. They allow to distinguish them according to the type, technological process used, maturity level, origin, microbiological contamination, adulteration, and other quality properties (reviewed in Berna 2010; Loutfi et al. 2015; Schaller et al. 1998; Wilson and Baietto 2009; Zohora et al. 2013).

In the case of authentic or traditional food, the aroma of a product should be specific enough to discriminate an original one from its fraud or adulterated counterpart. Many reports show that e-nose is a very promising tool for monitoring authenticity of food products. In the present paper, the most recent applications of e-nose (mostly from last 10 years) for determination of food authenticity, including adulteration and origin confirmation, are presented (Table 1) and discussed. Applications of e-noses in quality control, monitoring technological process, ageing, spoilage, and others are not presented. They are reviewed in, e.g. Berna (2010), Loutfi et al. (2015), Schaller et al. (1998), Wilson and Baietto (2009), and Zohora et al. (2013). Several other studies are referenced, e.g. in Liu et al. (2012), Pizzoni et al. (2015), Qiu et al. (2015), and Xiao et al. (2014). The results of some studies concerning the authenticity of food were summarized by Dymerski et al. (2011), Peris and Escuder-Gilabert (2009), and Śliwińska et al. (2014) as one of the aspects of e-nose applications in food analysis. In a very recent publication of Śliwińska et al. (2016b) on advances in e-noses and e-tongues for food authenticity testing, there are much fewer examples of e-nose applications concerning food adulteration and origin confirmation than presented in this review.

In this review, 46 examples of the applications of e-noses of various configurations for authenticity testing of food are presented and discussed. It is not possible to discuss the results of 
Table 1 Applications of electronic noses for monitoring authenticity (adulteration and origin) of foods

\begin{tabular}{|c|c|c|c|c|c|}
\hline & Product & Purpose of analysis & E-nose configuration & Multivariate data analysis & Reference \\
\hline 1. & Milk & $\begin{array}{l}\text { Adulteration of skimmed milk } \\
\text { with water or reconstituted } \\
\text { skimmed milk powder }\end{array}$ & $\begin{array}{l}\text { A PEN2 e-nose (portable electronic } \\
\text { nose, Win Muster Airsense (WMA), } \\
\text { Analytics Inc., Schwerin, Germany) } \\
\text { with } 10 \text { MOS sensors }\end{array}$ & PCA, LDA & Yu et al. 2007 \\
\hline 2. & Cheese & Geographical origin & $\begin{array}{l}\text { An e-nose with MS detector (a SMart } \\
\text { Nose, LDZ, Marin-Epagnier, } \\
\text { Switzerland) }\end{array}$ & PCA & Pillonel et al. 2003 \\
\hline 3. & Cheese & $\begin{array}{l}\text { Authenticity of cheese marked } \\
\text { with PDO (Picorino) }\end{array}$ & $\begin{array}{l}\text { An electronic olfactory system (EOS } \\
507, \text { Sacmi Imola S.C., Imola, } \\
\text { Bologna, Italy) with } 6 \text { MOS sensors }\end{array}$ & PCA, ANN & Cevoli et al. 2011 \\
\hline 4. & Cheese & $\begin{array}{l}\text { Origin and authenticity of } \\
\text { cheese marked with PDO } \\
\text { (Oscypek) }\end{array}$ & $\begin{array}{l}\text { SPME-MS; Carboxen/PDMS fibre } \\
\text { was used for extraction of volatiles }\end{array}$ & PCA, LDA, SIMCA, SVM & Majcher et al. 2015 \\
\hline 5. & Olive oil & $\begin{array}{l}\text { Quality, variety, geographical } \\
\text { origin }\end{array}$ & $\begin{array}{l}\text { An array of } 16 \text { conducting polymer } \\
\text { gas sensors with a static HS } \\
\text { autosampler (a purposely } \\
\text { designed system) }\end{array}$ & PCA & $\begin{array}{l}\text { Guadarrama et } \\
\text { al. } 2001\end{array}$ \\
\hline 6. & Virgin olive oil & $\begin{array}{l}\text { Adulteration with sunflower } \\
\text { and olive pomace oils }\end{array}$ & $\begin{array}{l}\text { Alpha MOS electronic nose system, } \\
\text { FOX } 3000 \text { (France) with } \\
12 \text { MOX sensors }\end{array}$ & PCA, LDA, QDA, ANN & $\begin{array}{l}\text { Cerrato Oliveros } \\
\quad \text { et al. } 2002\end{array}$ \\
\hline 7. & Virgin olive oil & Geographical origin & $\begin{array}{l}\text { An HS-MS e-nose (a specially } \\
\text { designed system) }\end{array}$ & PCA, LDA, Step-LDA & $\begin{array}{l}\text { Cerrato Oliveros } \\
\text { et al. } 2005\end{array}$ \\
\hline 8. & Virgin olive oil & $\begin{array}{l}\text { Adulteration with sunflower } \\
\text { and olive pomace oils }\end{array}$ & $\begin{array}{l}\text { An HS-MS e-nose ChemSensor } \\
4440 \text { (Gerstel, Mülheim an der } \\
\text { Ruhr, Germany) }\end{array}$ & LDA & Lorenzo et al. 2002 \\
\hline 9. & $\begin{array}{l}\text { Olive oil (pure refined } \\
\text { and extra virgin) }\end{array}$ & Adulteration with hazelnut oil & $\begin{array}{l}\text { An HS-MS e-nose ChemSensor } \\
4440 \text { (Gerstel, Mülheim an der } \\
\text { Ruhr, Germany) }\end{array}$ & CA, SIMCA, PLS, PCR, & Peña et al. 2005 \\
\hline 10. & Virgin olive oil & $\begin{array}{l}\text { Confirmation of geographical } \\
\text { origin and authentication } \\
\text { (PDO-labelled samples) }\end{array}$ & $\begin{array}{l}\text { An e-nose (model } 3320 \text { Applied } \\
\text { Sensor Lab Emission Analyser, } \\
\text { Applied Sensor Co., Linkoping, } \\
\text { Sweden) with } 10 \text { (MOSFET) } \\
\text { and } 12 \text { MOS sensors }\end{array}$ & PCA, CP-ANN & Cosio et al. 2006 \\
\hline 11. & Virgin olive oil & Adulteration with hazelnut oil & $\begin{array}{l}\text { Alpha MOS e-nose system (Fox } \\
\text { 4000,Alpha MOS, Toulouse, } \\
\text { France) }\end{array}$ & PCA, PLS & $\begin{array}{l}\text { Mildner-Szkudlarz } \\
\text { and Jeleń } 2008\end{array}$ \\
\hline 12. & Virgin olive oil & $\begin{array}{l}\text { Adulteration with rapeseed } \\
\text { and sunflower oils }\end{array}$ & $\begin{array}{l}\text { Alpha MOS e-nose system (Fox } \\
\text { 4000, Alpha MOS, Toulouse, } \\
\text { France) }\end{array}$ & PCA, PLS & $\begin{array}{l}\text { Mildner-Szkudlarz } \\
\text { and Jeleń } 2008\end{array}$ \\
\hline 13. & Virgin olive oil & $\begin{array}{l}\text { Confirmation of geographical } \\
\text { origin }\end{array}$ & $\begin{array}{l}6 \text { MOS sensors (a specially } \\
\text { designed system) }\end{array}$ & PCA, LDA & Haddi et al. 2011 \\
\hline 14. & Sesame oil & Adulteration with maize oil & $\begin{array}{l}\text { PEN2, MOS Electronic Nose } \\
\text { System with } 10 \text { sensors (portable } \\
\text { electronic nose II, Airsense } \\
\text { Corporation, Germany) }\end{array}$ & $\begin{array}{l}\text { PCA, FLT, Step-LDA, } \\
\text { SFW, PNN, BPNN, } \\
\text { GRNN }\end{array}$ & Hai and Wang 2006 \\
\hline 15. & Palm olein & $\begin{array}{l}\text { Adulteration of refined, } \\
\text { bleached, and deodorized } \\
\text { (RBD) palm olein with lard }\end{array}$ & $\begin{array}{l}\text { A surface acoustic wave (SAW) } \\
\text { sensing e-nose (zNose }{ }^{\mathrm{TM}} 4100 \\
\text { vapour analysis system, } \\
\text { Electronic Sensor Technology, } \\
\text { Newbury Park, CA, USA) }\end{array}$ & Regression analysis & Che Man et al. 2005 \\
\hline 16. & Virgin coconut oil & $\begin{array}{l}\text { Adulteration with RBD palm } \\
\text { kernel olein }\end{array}$ & $\begin{array}{l}\text { SAW sensing e-nose } \text { (zNose }^{\mathrm{TM}} \\
\text { 7000, Electronic Sensor } \\
\text { Technology, Newbury Park, } \\
\text { CA, USA) }\end{array}$ & PCA, PLS & Marina et al. 2010 \\
\hline 17. & Argan oil & Adulteration with sunflower oil & $\begin{array}{l}\text { A MOS gas e-nose system based } \\
\text { on a 5-sensor array (a specially } \\
\text { designed system) }\end{array}$ & PCA, DFA, SVMs & Bougrini et al. 2014 \\
\hline 18. & Flax seed oil & $\begin{array}{l}\text { Differently processed oils for } \\
\text { fraud detection }\end{array}$ & $\begin{array}{l}\text { A FOX } 3000 \text { electronic nose (Alpha } \\
\text { MOS, Toulouse, France) with } \\
\text { array of } 18 \text { MOX sensors }\end{array}$ & PCA & Wei et al. 2015 \\
\hline 19. & Lard & $\begin{array}{l}\text { Differentiation from chicken, } \\
\text { beef, and mutton fats as well } \\
\text { as adulteration of lard with } \\
\text { chicken fat }\end{array}$ & $\begin{array}{l}\text { A zNose } \\
\text { system, Electronic Sensor } \\
\text { Technology, Newbury Park, } \\
\text { USA, with SAW sensor) }\end{array}$ & PCA & Nurjuliana et al. 2011a \\
\hline
\end{tabular}


Table 1 (continued)

\begin{tabular}{|c|c|c|c|c|c|}
\hline & Product & Purpose of analysis & E-nose configuration & Multivariate data analysis & Reference \\
\hline 20. & Meat and meat products & $\begin{array}{l}\text { Halal authentication and } \\
\text { verification }\end{array}$ & $\begin{array}{l}\text { A zNose }{ }^{\mathrm{TM}} \text { (7100 vapor analysis } \\
\text { system, Electronic Sensor } \\
\text { Technology, Newbury Park, USA, } \\
\text { with SAW sensor) }\end{array}$ & PCA & Nurjuliana et al. 2011b \\
\hline 21. & Meat & $\begin{array}{l}\text { Adulteration of minced mutton } \\
\text { with pork }\end{array}$ & $\begin{array}{l}\text { A PEN2 e-nose (portable electronic } \\
\text { nose II, Airsense Corporation, } \\
\text { Germany) with } 10 \text { MOS sensors }\end{array}$ & $\begin{array}{l}\text { CDA, BDA, PLS, MLR, } \\
\text { BPNN }\end{array}$ & Tian et al. 2013 \\
\hline 22. & Ham & $\begin{array}{l}\text { Differentiation of hams marked } \\
\text { with PDO }\end{array}$ & $\begin{array}{l}\text { A PEN2 e-nose (portable electronic } \\
\text { nose), Win Muster Airsense } \\
\text { (WMA) Analytics Inc., Schwerin, } \\
\text { Germany) with } 10 \text { MOS sensors }\end{array}$ & PCA & Laureati et al. 2014 \\
\hline 23. & Honey & Confirmation of botanical origin & $\begin{array}{l}\text { An e-nose with MS detector (a } \\
\text { SMart Nose (LDZ, Marin-Epagnier, } \\
\text { Switzerland); three sampling } \\
\text { modes: SHS, SPME, INDEX }\end{array}$ & PCA, DFA & Ampuero et al. 2004 \\
\hline 24. & Honey & $\begin{array}{l}\text { Botanical origin and } \\
\text { adulteration with cane sugar }\end{array}$ & $\begin{array}{l}\text { The Cyranose320 e-nose (Smith } \\
\text { Detection }{ }^{\mathrm{TM}} \text { ) with } 32 \text { non-selective } \\
\text { sensors of different types of } \\
\text { polymer matrix, blended with } \\
\text { carbon black }\end{array}$ & PCA, LDA & Zakaria et al. 2011 \\
\hline 25. & Honey & $\begin{array}{l}\text { Adulteration with beet and } \\
\text { cane sugar }\end{array}$ & $\begin{array}{l}\text { The Cyranose } 320 \text { e-nose (Smith } \\
\text { Detection }^{\mathrm{TM}} \text { ) with } 32 \text { non-selective } \\
\text { sensors of different types of } \\
\text { polymer matrix }\end{array}$ & PCA, LDA & Subari et al. 2012 \\
\hline 26. & Honey & $\begin{array}{l}\text { Adulteration with beet and } \\
\text { cane sugar }\end{array}$ & $\begin{array}{l}\text { The Cyranose } 320 \text { e-nose (Smith } \\
\text { Detection }^{\mathrm{TM}} \text { ) with } 32 \text { non-selective } \\
\text { sensors of different types of } \\
\text { polymer matrix }\end{array}$ & ANN & Subari et al. 2014 \\
\hline 27. & Honey & $\begin{array}{l}\text { Adulteration with rice syrup } \\
\text { and rape honey }\end{array}$ & $\begin{array}{l}\text { The FOX } 4000 \text { e-nose (Alpha MOS, } \\
\text { Toulouse, France) }\end{array}$ & LDA & Pei et al. 2015 \\
\hline 28. & Honey & Botanical origin confirmation & $\begin{array}{l}\text { A Fox } 4000 \text { (Alpha MOS, Toulouse, } \\
\text { France) with } 3 \text { MOX sensor } \\
\text { chambers equipped with } 18 \text { sensors }\end{array}$ & PCA, DFA, LS-SVM, PLS & Huang et al. 2015 \\
\hline 29. & Honey & $\begin{array}{l}\text { Confirmation of botanical } \\
\text { origin and adulteration with } \\
\text { rice and corn syrups }\end{array}$ & $\begin{array}{l}\text { A flash GC e-nose (Heracles, Alpha } \\
\text { MOS, Toulouse, France) }\end{array}$ & PCA, SVM, PLS & Gan et al. 2016 \\
\hline 30. & Orange juice & $\begin{array}{l}\text { Authentication of Valencia } \\
\text { orange juices }\end{array}$ & $\begin{array}{l}\text { A FOX } 3000 \text { electronic nose (Alpha } \\
\text { MOS, Toulouse, France) with } \\
2 \text { rooms of } 12 \text { MOS sensors. }\end{array}$ & PCA, FDA & Steine et al. 2001 \\
\hline 31. & Cherry tomato juice & $\begin{array}{l}\text { Adulteration with overripe } \\
\text { tomato juice }\end{array}$ & $\begin{array}{l}\text { A PEN } 2 \text { e-nose (Airsense Analytics, } \\
\text { GmBH, Schwerin, Germany) with } \\
10 \text { different MOS }\end{array}$ & PCA, CA & Hong et al. 2014 \\
\hline 32. & Wine & $\begin{array}{l}\text { Adulteration with methanol, } \\
\text { ethanol, and other wines }\end{array}$ & $\begin{array}{l}\text { A multisensor array based on four } \\
\text { thin-film semiconducting MOS, } \\
\text { surface-activated by } \mathrm{Pt}, \mathrm{Au}, \mathrm{Pd} \\
\text { Bi metal catalysts }\end{array}$ & PCA & $\begin{array}{l}\text { Penza and } \\
\quad \text { Cassano } 2004\end{array}$ \\
\hline 33. & Wine & Origin, variety, and ageing & $\begin{array}{l}\text { A HS-MS e-nose (Hewlett-Packard, } \\
\text { Waldbronn, Germany) }\end{array}$ & PCA, SIMCA & Martí et al. 2004 \\
\hline 34. & Wine & Variety confirmation & $\begin{array}{l}\text { A specially designed system of } 16 \\
\mathrm{SnO}_{2} \text { thin film sensors with } \\
\text { thicknesses between } 200 \text { and } \\
800 \mathrm{~nm} \text {. Some sensors were } \\
\text { doped with chromium and indium } \\
\text { either as surface or an intermediate } \\
\text { layer }\end{array}$ & PCA, PNN & Lozano et al. 2007 \\
\hline 35. & Wine & Origin confirmation & $\begin{array}{l}\text { A portable e-nose containing two } \\
\text { different micromachined resistive } \\
\text { sensor arrays: (1) a polysilicon } \\
\text { integrated heater and (2) with a } \\
\text { platinum one; each sensor array } \\
\text { contains four tin oxide sensors } \\
\text { (a specially designed system) }\end{array}$ & PCA, PNN & Aleixandre et al. 2008 \\
\hline 36. & Wine & $\begin{array}{l}\text { Geographical origin } \\
\text { confirmation }\end{array}$ & $\begin{array}{l}\text { A FOX } 3000 \text { e-nose (Alpha MOS, } \\
\text { Toulouse, France), with } 12 \\
\text { semiconducting MOS sensors }\end{array}$ & LDA & Berna et al. 2009 \\
\hline
\end{tabular}


Table 1 (continued)

\begin{tabular}{|c|c|c|c|c|c|}
\hline & Product & Purpose of analysis & E-nose configuration & Multivariate data analysis & Reference \\
\hline 37. & Wine & Geographical origin confirmation & $\begin{array}{l}\text { MS-based e-nose (Chemical Sensor } \\
\text { HP } 4440 \text { (Hewlett Packard) }\end{array}$ & PCA, PLS-DA, Step-LDA & Cynkar et al. 2010 \\
\hline 38. & Wine & $\begin{array}{l}\text { Confirmation of geographical } \\
\text { origin, grapevine variety, or } \\
\text { blends and adulteration with } \\
\text { water }\end{array}$ & $\begin{array}{l}\text { A flash GC e-nose (Heracles, Alpha } \\
\text { MOS, Toulouse, France) }\end{array}$ & DFA & $\begin{array}{l}\text { Antoce and } \\
\quad \text { Namolosanu } 2011\end{array}$ \\
\hline 39. & Spirit & $\begin{array}{l}\text { Geographical origin confirmation } \\
\text { (Chinese Tongshan kaoliang } \\
\text { spirit) }\end{array}$ & $\begin{array}{l}\text { A flash GC e-nose (Heracles II, } \\
\text { Alpha MOS, Toulouse, France) }\end{array}$ & PCA, DFA, & Peng et al. 2015 \\
\hline 40. & Spirit & $\begin{array}{l}\text { Botanical origin confirmation } \\
\text { (rye, triticale, wheat, maize } \\
\text { agricultural distillates) }\end{array}$ & $\begin{array}{l}\text { A flash GC e-nose (Heracles II, } \\
\text { Alpha MOS, Toulouse, France) }\end{array}$ & PCA, DFA, SIMCA, SQC & Wiśniewska et al. 2016 \\
\hline 41. & Liqueur & $\begin{array}{l}\text { Authenticity confirmation } \\
\text { (traditional Polish cherry } \\
\text { liqueur nalewka) }\end{array}$ & $\begin{array}{l}\text { A flash GC e-nose (Heracles II, } \\
\text { Alpha MOS, Toulouse, France) }\end{array}$ & PCA, DFA, SIMCA, SQC & Śliwińska et al. 2016 \\
\hline 42. & Vinegar & $\begin{array}{l}\text { Authentication based on product } \\
\text { age (Aceto Balsamico } \\
\text { Tradizionale di Modena) }\end{array}$ & $\begin{array}{l}\text { HS-MS (Hi-Tech Applications, } \\
\text { Brescia, Italy) }\end{array}$ & $\begin{array}{l}\text { PARAFAC, PCA, LDA, } \\
\text { SIMCA }\end{array}$ & Cocchi et al. 2007 \\
\hline 43. & Tea & Geographical origin & $\begin{array}{l}\text { A NST } 3320 \text { type e-nose with } \\
23 \text { sensors (10 MOSFET, } \\
12 \text { MOS, and a sensor for } \\
\text { relative humidity measurements) } \\
\text { (Applied Sensor A.G., Sweden) }\end{array}$ & PCA, PLS & Kovács et al. 2010 \\
\hline 44. & Coffee & $\begin{array}{l}\text { Variety confirmation (Arabica } \\
\text { and Robusta) }\end{array}$ & $\begin{array}{l}\text { A PEN2 e-nose (portable } \\
\text { electronic nose, Win Muster } \\
\text { Airsense (WMA) Analytics } \\
\text { Inc., Schwerin, Germany) with } \\
10 \text { MOS sensors }\end{array}$ & PCA, LDA & Buratti et al. 2015 \\
\hline 45. & Spice mixtures & $\begin{array}{l}\text { Adulteration with curry or } \\
\text { garlic }\end{array}$ & $\begin{array}{l}\text { An e-nose with a chip array of } \\
38 \text { MOS sensor segments based } \\
\text { on gas sensitive doped tin oxide } \\
\text { (KAMINA-type, Yson } \mathrm{GmbH} \text { ). }\end{array}$ & PCA, LDA & Banach et al. 2012 \\
\hline 46 & Saffron & $\begin{array}{l}\text { Adulteration with safflower, } \\
\text { yellow style, and corn stigma } \\
\text { (silk) coloured with beetroot } \\
\text { dye }\end{array}$ & $\begin{array}{l}\text { An e-nose with } 6 \text { MOS sensors } \\
\text { (designed system) }\end{array}$ & PCA, ANN & Heidarbeigi et al. 2015 \\
\hline
\end{tabular}

all published studies especially because new ones still appear. The most important groups of food products, i.e. milk products, plant oils, animal fats and meat, honey, alcoholic beverages, and others, are included. We mainly focused on products that are unique because of their botanical or geographical origin, as well as on those the authenticity of which could be the subject of manipulations. This review will allow the readers to get to know how e-noses combined with chemometrics could be potentially used in the field of food authenticity testing.

\section{Application of e-Nose in Food Authenticity Testing}

\section{Milk Products}

Volatile compounds found in different milk products include native volatile compounds of milk and volatile compounds produced in the final product during production or maturation (Pillonel et al. 2003). Some products contain especially high concentration of certain volatile compounds, but usually they do not allow discrimination of the same type of products.

$\mathrm{Yu}$ et al. (2007) found that it is possible to detect adulteration of skimmed milk with reconstituted milk powder or water using e-nose with 10 metal oxide semiconductor (MOS) sensors. Results of linear discriminant analysis (LDA) and principal component analysis (PCA) of the data obtained from the e-nose revealed that adulteration of skimmed milk with reconstituted milk powder or water can be detected up to 4 days of milk storage.

Authenticity of Emmental cheese from different European regions was investigated by Pillonel et al. (2003) using gas chromatography with mass spectrometer (GC-MS) and a flame ionization detector (FID), as well as an MS-based enose. They reported that cheese from various regions could be differentiated from each other using volatile compounds which were more or less specific to one or two regions. Butan-2-one, butan-2-ol, 3-hydroxybutanone, and octane were, e.g. pointed as markers for Swiss cheeses. However, GC-MS with a purge-and-trap (P\&T) technique was indicated by authors as a very expensive and time-consuming tool; thus, 
they looked for less costly methods such as a MS-based enose. Using PCA, 90 and $91 \%$ of correct classifications were obtained for the Swiss Emmental and Emmental from other regions, respectively. By discriminating each non-Swiss and Swiss region, correct classifications of $90-100 \%$ were obtained for Swiss Emmental cheese and 83-100\% for Emmental cheese from other regions. The authors suggested that the discrimination should be improved by the usage of such trained classification techniques as discriminant function analysis (DFA) and LDA in combination with a bigger database. They also proposed that the sensitivity of the analysis, and thus the potential of e-nose as an analytical tool for determination of authenticity of Emmental cheese, could be improved by the pre-concentration of the headspace (HS) before injecting it into the MS detector.

Various cheeses in Europe are PDO products. Alike other products, they are a subject of adulteration. Italian PDO Picorino cheeses were successfully classified according to their manufacturing techniques and ripening time using an enose based on six MOS sensors and an artificial neural network (ANN) method. The most effective pre-treatment data procedure before ANN model preparation was PCA with a classification performance of $100 \%$ and a root mean square error (RMSE) value of 0.024 . Moreover, the classification capability of the applied e-nose coupling with ANN was even better than the capability of the technique based on analysis of volatile compounds such as GC-MS (Cevoli et al. 2011).

Majcher et al. (2010) investigated the volatile profiles of Polish Oscypek cheese with a symbol of PDO and Oscypeklike cheeses (adulterated Oscypek cheeses). They found that the aroma of Oscypek was more developed than the aroma of other cheeses. Moreover, industrially produced Oscypek-like cheeses were less developed in flavour than artisan cheeses. Authenticity of Polish Oscypek was determined using an enose based on solid-phase microextraction and mass spectrometry (SPME-MS). SPME-MS involved volatile extraction by SPME with subsequent characterization of mass spectra without separation of volatile compounds using GC (Majcher et al. 2015). It was reported that the aroma of different cheeses was specific and discrimination of Oscypek-like cheeses from traditional PDO Oscypek is possible. Application of multivariate analyses of SPME-MS data including PCA, LDA, soft independent modelling of class analogy (SIMCA), and support vector machine (SVM) allowed successful discrimination of Oscypek cheeses from adulterated ones and led the authors to the conclusion that the e-nose applied in their study can be used to detect mislabelling and adulteration of PDO Oscypek cheeses (Majcher et al. 2015).

\section{Plant Oils}

The adulteration of an expensive and high-quality oil with a cheaper one or plant fats containing lard or tallow is a frequent problem gaining attention of oil suppliers, regulatory agencies, and consumers. The Codex Alimentarius Specification for Fats and Oils lists the range of fatty acids in various oils and fats; thus, it is the international base for checking the purity of these products (Che Man et al. 2005). However, comparison of fatty acid composition may not be sufficient for fat or oil authenticity confirmation.

Authenticity studies with an e-nose have been successfully performed for the differentiation of virgin olive oils. Among the most frequent adulteration of virgin olive oils are those with sunflower, maize, olive pomace, and hazelnut oils (Cerrato Oliveros et al. 2002). Adulteration with hazelnut oil is one of the most difficult to detect because of its similar composition (fatty acids, triacylglycerols, and total sterols) to olive oil (Peña et al. 2005).

An example of application of an e-nose for olive oils is the study by Guadarrama et al. (2001) who used a sensor array based on 16 conducting polymer gas sensors to discriminate the quality, variety, and geographical origin of olive oils. The PCA revealed that the e-nose applied in the study has been able to distinguish not only different-quality olive oils (lampante, ordinary, virgin, and extra virgin) but also Spanish olive oils produced from different varieties of olives and originated from different geographical areas.

Adulteration of virgin olive oil with sunflower and olive pomace oils was also investigated by Cerrato Oliveros et al. (2002). They used the signals obtained by an e-nose with a selected array of 12 metal oxide (MOX) sensors and multivariate chemometric techniques such as quadratic discriminant analysis (QDA), LDA, and ANN. Good results were obtained in the discrimination of non-adulterated and adulterated olive oils with the possibility of identifying the type of oil adulterant. The models generated using the discriminant analysis techniques provided good results with prediction rates higher than $95 \%$. For particular cases, promising results were obtained regarding quantification of adulteration percentage.

The same authors (Cerrato Oliveros et al. 2005) used a HSMS-based e-nose for the discrimination of extra virgin olive oils originating from five different Mediterranean areas. The headspace generation temperature was $40^{\circ} \mathrm{C}$, and the selected features were fragment ions strictly connected with the typical olive oil volatile components and with the related cultivar. Chemometric analysis of data obtained for 105 samples was performed using PCA, LDA, and stepwise LDA (step-LDA). Using step-LDA, $93.6 \%$ of samples were correctly classified and $90.5 \%$ were correctly predicted by a cross-validation procedure. Moreover, $80.0 \%$ of samples from an external test set were correctly assigned.

Lorenzo et al. (2002) proposed an application of a headspace coupled with a mass spectrometer (HS-MS e-nose) for the detection of sunflower and olive pomace oil adulteration at the level of 5-60\% in 89 samples of olive oils. For preparation of adulterated samples, 32 commercial olive oils (virgin and 
refined), originating from different suppliers, were used. The LDA analysis of e-nose data allowed distinguishing the type of adulteration (sunflower or olive pomace oil) with $100 \%$ success in classification and $99 \%$ success in prediction. Discrimination between non-adulterated and adulterated olive oil samples with $100 \%$ success in classification and $98 \%$ success in prediction was also reported.

A similar technique was successfully used by Peña et al. (2005) for the detection of adulteration of refined and virgin olive oils with hazelnut oil at the minimum adulteration levels of 7 and $15 \%$, respectively. The authors used HS-MS e-nose to analyse oil samples and various chemometric recognition and regression techniques for data treatment such as SIMCA, cluster analysis (CA), partial least squares (PLS), and principal component regression (PCR). It was reported that the PLS model provided lower standard error of prediction (SEP) value than PCR and higher percentages of explained data variance. Validation of the proposed method revealed good accuracy of both models. For both olive and virgin olive oils, SEP values of 1.3 and $1.4 \%$ were obtained with PLS and PCR models, respectively. The PLS model was applied to detect the adulteration of commercial olive oils with hazelnut oil. No positive results were obtained for the virgin olive oils, but six olive oils were found to be adulterated with hazelnut oil at the level from 23 to $45 \%(w / w)$.

Cosio et al. (2006) used an e-nose to characterize the geographical origin of Italian Garda extra virgin olive oil distinguished as PDO since 1998. A classification model, differentiating 36 extra virgin olive oils of Garda from 17 extra virgin olive oils of several regions of Italy and Europe, has been generated by means of counter-propagation artificial neural networks (CP-ANNs). They created a classification model with two classes (not-Garda and Garda extra virgin olive oils) that was proposed as a good tool to describe PDO Garda extra virgin olive oil uniqueness and protect Garda PDO against adulteration.

Mildner-Szkudlarz and Jelen (2008) assessed the potential of three methods of volatile compound analysis with subsequent PCA to discriminate extra virgin olive oil adulterated with hazelnut oil. They used comparison of SPME-fast-GCFID chromatograms of volatiles and sample headspace comparison using an e-nose based on six MOS sensors (HS-E nose) and an e-nose based on SPME-MS. Volatile compounds were identified by the SPME-GC/MS technique. The same techniques (HS-E nose, SPME-MS, and SPME-GC/MS) were also applied to detect adulteration of olive oil with rapeseed and sunflower oils (Mildner-Szkudlarz and Jeleń 2010). In both studies, PCA and PLS analyses were applied to the data from two e-noses and chromatographic analyses. The authors reported that all methods of oil aroma analysis allowed discrimination between non-adulterated and adulterated samples and detection of different contents $(5-50 \% v / v)$ of hazelnut, rapeseed, and sunflower oil adulterants in olive oil (Mildner-
Szkudlarz and Jeleń 2008; Mildner-Szkudlarz and Jeleń 2010). When HS-E nose data were used, the PLS model predicted hazelnut adulteration of virgin olive oil with a correlation coefficient of 0.997 and an accuracy of $2.85 \%$ (MildnerSzkudlarz and Jeleń 2008), rapeseed oil adulteration with a correlation coefficient of 0.989 and an average error of $4.41 \%$, and sunflower oil adulteration with a correlation coefficient of 0.990 and an average error of $4.20 \%$ (Mildner-Szkudlarz and Jelen 2010). When SPME-MS data were used, PLS models predicted rapeseed oil adulteration of virgin oil with a correlation coefficient of 0.994 and an average error of $3.12 \%$, whereas those in the case of sunflower adulteration were 0.992 and $3.26 \%$, respectively (Mildner-Szkudlarz and Jeleń 2010). A good agreement between chromatographic analyses (SPME-fast-GC-FID and/or SPME-GC/MS) and e-nose (HSE nose or SPME-MS) data was found, but the two latter methods were less time-consuming than GC methods; thus, they seem to be very promising for routine detection of extra virgin olive oil adulteration with cheaper plant oils (MildnerSzkudlarz and Jeleń 2008; Mildner-Szkudlarz and Jeleń 2010).

The geographical origin of Moroccan virgin olive oils was confirmed in the study of Haddi et al. (2011) by an e-nose based on six MOS sensors and pattern recognition techniques such as PCA and LDA. They found that especially LDA gives good separation of tested olive oils. Cross-validation using a leave-one-out approach was applied for the LDA model, and an accuracy of $96.3 \%$ in the recognition of virgin olive oils from Morocco was obtained.

An e-nose based on the system of 10 MOS sensors was used for the detection and determination of the adulteration level of sesame oil with maize oil (Hai and Wang 2006). The level of adulteration was in the range from 10 to $90 \%$. PCA, step-LDA, Fisher linear transformation (FLT), and selection by Fisher weights (SFW) were used as feature extraction methods. For pattern recognition, LDA, back propagation neural networks (BPNNs), probabilistic neural networks (PNNs), and general regression neural networks (GRNNs) were applied. It was found that in the classification by LDA or PNN, FLT was the most effective feature extraction method, whereas step-LDA and FLT were the most suitable for BPNN and GRNN, respectively. It was also reported that BPNN after training could quantitatively predict the adulteration more precisely than GRNN. On the other hand, GRNN with FLT (as its feature extraction method) and without iterative training could also give acceptable results.

Che Man et al. (2005) investigated the potential use of surface acoustic wave (SAW) sensing e-nose ( $\left(\mathrm{ZNose}^{\mathrm{TM}}\right)$ for the detection of lard adulteration in refined, bleached, and deodorized (RBD) palm olein. They also determined the changes in fatty acid composition of RBD palm olein adulterated with lard at the level from 1 to $20 \%(w / w)$. They reported that the changes in fatty acid composition are not sufficiently a 
good parameter to prove the adulteration of RBD palm olein with lard, because similar changes in fatty acid composition were observed for RBD palm oil adulterated with chicken fat (Marikkar et al. 2002). However, adulteration of RBD palm olein with lard (as low as 1\%) can be detected and quantitatively determined using zNose ${ }^{\mathrm{TM}}$.

$\mathrm{zNose}^{\mathrm{TM}}$ was also used to detect the adulteration of virgin coconut oil with RBD palm kernel olein at the level from 1 to $20 \%(w / w)$ (Marina et al. 2010). The e-nose peaks were obtained from the sensor signal values, which represented the concentration of specific volatile compounds. The authors selected peaks that changed according to the adulterant concentration and considered them as the adulterant peaks. They were tentatively identified as 3-hexenal, trimethyl pyrazine, citronellal, decanol, 2-undecenal, methyl dodecanoate, deltadecalactone, and butyl laurate using n-alkanes as the standards and Kovats indices stored in the database of the Microsense software. The presence of the adulterant was sensed just at $1 \%$. The relationship between adulterant peaks and the percentage of added palm kernel olein was calculated, and the best relationship was obtained for the peak tentatively identified as methyl dodecanoate $\left(R^{2}=0.91\right)$. PCA allowed the separation of pure virgin coconut oils from adulterated samples, and the PLS model with a $R^{2}$ of 0.91 indicated the potential of an e-nose as a tool in the routine control of virgin coconut oil adulteration.

The possibility of application of an e-nose based on MOS sensors (five tin dioxide gas (TGS) sensors) and pattern recognition techniques such as PCA, DFA, and SVM to detect adulteration of argan oil with sunflower oil (from 10 to $70 \%$ ) was reported by Bougrini et al. (2014). Results of PCA and DFA performed on the e-nose data showed differentiation between pure and adulterated argan oils. SVM and the oneagainst-one classification method were implemented to build the classification model. SVM classification results showed acceptable success rates of $91.67 \%$ for comestible argan oil and $83.34 \%$ for cosmetic argan oil.

The results of Wei et al. (2015) concerning the volatile compounds of differently processed flaxseed oils (coldpressed, hot-pressed, and solvent-extracted) showed that the major volatile compounds could be used as chemical markers to recognize differently processed oils by PCA. The marker compounds that contributed to the discrimination of flaxseed oils were hexanal, (E,E)-2,4-pentadienal, (E,E)-2,4heptadienal, 6-hydroxy-2-hexanone, 1-hexanol, methyl-pyrazine, nonanal, 2,3-pentanedione, 1-butanol, acetic acid, hexanoic acid, and ethyl acetate. PCA based on these volatile compounds, as well as on the data obtained using an e-nose based on 18 MOX sensors, allowed distinguishing differently processed flaxseed oils. The authors found good consistency among the results obtained using GC-MS, e-nose, and sensory evaluation, suggesting the good potential of the e-nose for evaluation of flax seed oil quality and detection of frauds.

\section{Animal Fats and Meat}

Identification of meat species in minced and comminuted meat products is relevant for consumers from economic (price), health (allergens), and religious reasons. Nurjuliana et al. (2011b) proposed the application of an e-nose for halal authentication. Market of halal food has recently increased especially in the major Muslin countries. One of the categories of nonhalal food is pig derivatives, including all its by-products (Rohman and Che Man 2012). It was found that aromas of lard and other animal fats such as beef, mutton, and chicken fats are sufficiently specific to differentiate them using zNose ${ }^{\mathrm{TM}}$ (Nurjuliana et al. 2011a). zNose ${ }^{\mathrm{TM}}$ gives a two-dimensional olfactory image (a Vapor Print ${ }^{\mathrm{TM}}$ ) that was used to quantitatively monitor the changes that occurred when chicken fat was added to lard. This image can be regarded as the chemical signature of an aroma of a substance. It is the graphical display of the SAW detector sensor converted into a planar format: the angular variable is the retention time and the radial variable is the SAW detector frequency (Marina et al. 2010; Nurjuliana et al. 2011a). Using PCA, the authors were able to differentiate lard fat adulterated with chicken at the level from 1 to $80 \%(w / w)$.

The authors from the same group (Nurjuliana et al. 2011b) successfully used zNose ${ }^{\mathrm{TM}}$ and PCA for identification and differentiation of pork meat and pork sausages from mutton, beef, and chicken meats. They also suggested that heptanal had a major influence on the discrimination of pork from other types of meat and sausages.

The analysis of pork adulteration in minced mutton using $\mathrm{pH}$ and colour measurements as well as an e-nose based on MOS sensors was done by Tian et al. (2013). Different chemometric methods were used to evaluate the e-nose application in classification of the adulteration and to build a model predicting the content of pork in minced mutton. The authors found that step-LDA was the most effective feature extraction method. Multiple linear regression (MLR), PLS analysis, and BPNN showed high capacity in predicting pork content in minced mutton with a $R^{2}$ higher than 0.9092 and a RMSE lower than $10.94 \%$, but the model built by BPNN was more precise in predicting the adulteration $\left(R^{2}\right.$ higher than 0.97$)$.

The authenticity of Italian PDO dry-cured Parma, San Daniele, and Toscano hams was investigated by Laureati et al. (2014). Their multi-disciplinary approach involved a sensory profile and physico-chemical, morphological, textural, and aromatic characteristics. For aroma analysis of hams, a portable e-nose (PEN2) with 10 MOS sensors was applied. PCA of enose data clearly differentiated PDO hams indicating that their aroma is specific enough to confirm their authenticity.

\section{Honey}

Adulteration of honey or mislabelling the botanical origin is considered one of the biggest problems with this product. 
Therefore, the confirmation of the botanical origin or detection of honey adulteration with sugar is of great importance for consumers. The results of several studies indicate that the quality of honey can be confirmed not only using laborious and time-consuming physico-chemical and chromatographic methods but also e-nose as the alternative.

An e-nose based on MS has been used by Ampuero et al. (2004) to control the botanical origin authenticity of honeys: acacia (Robinia ssp.), chestnut (Castanea ssp.), dandelion (Taraxacum ssp.), lime (Tilia ssp.), rape (Brassica ssp.), and fir (Abies ssp.). Three different sampling modes were applied: SPME, static headspace (SHS), and inside needle dynamic extraction (INDEX). The best classification of honeys was performed using ionic masses obtained by the e-nose with SPME presenting 98\% of correct classifications of honey samples, both with DFA and PCA. The SPME sampling mode gave heavier ionic masses than INDEX and SHS. It probably had a direct impact on classification. The authors also observed that the e-nose enabled sorting out of some aromadefective samples, e.g. fermented ones, which were also detected by sensory analysis, but not by the classical methods.

Zakaria et al. (2011) used an e-nose with 32 non-selective sensors of different types of polymer matrix, blended with carbon black, to classify honeys according to the botanical origin and to detect their adulteration with sugar syrup. Moreover, e-tongue was also applied. The PCA and LDA performed on data obtained from the e-nose and e-tongue discriminated polyfloral honey from sugar syrup and adulterated samples and monofloral honey from sugar syrup. PCA and LDA classification performed with all samples was not able to discriminate honeys of different floral origins, adulterated samples, and sugar syrup, but application of PNN enabled successful classification of all different samples with the highest classification result of $92.59 \%$. They also found that discrimination of samples using the e-nose was better than discrimination obtained by e-tongue, particularly when LDA was applied. The obtained results suggested also that pure and adulterated honeys could be better classified using fusion data obtained from e-nose and e-tongue.

The same e-nose system and chemometric methods were used by Subari et al. (2012). They compared the data obtained from an e-nose and FT-IR spectroscopy applied for the classification of Tualang honey and the determination of its adulteration with beetroot and cane sugars (from 20 to $80 \%$ ). They reported that LDA was better than PCA for honey classification based on e-nose data. After validation, the raw data obtained the highest classification accuracy $(76.5 \%)$ using stepLDA, whereas normalized data obtained the highest accuracy (74.9\%) using the direct LDA method. Fusion of e-nose and FT-IR spectroscopy data was also carried out. Honey classification using the step-LDA method based on e-nose and normalized low-level and intermediate-level FT-IR fusion data scored classification accuracies of 92.2 and $88.7 \%$, respectively, suggesting the potential of fusion methods to classify adulterated and pure honeys. In the second study, Subari et al. (2014) used the same approach, but used the ANN method to estimate the purity of 21 honey samples. The results showed that ANN performed on the e-nose and FT-IR fusion data was able to estimate the concentration of pure honey in adulterated honey solution with a mean absolute error of $6.9 \%$, whereas the mean absolute error using e-nose or FT-IR data separately was $15.0 \%$.

Huang et al. (2015) used an e-nose based on MOS sensors to identify the botanical origin of honeys as well as to determine some physico-chemical quality parameters. Honey samples originated from China and Australia. Fourteen botanical origins were indicated: jujube (Ziziphus jujuba), polyfloral honey from rape (Brassica napus), black locust (Robinia pseudoacacia), Chinese milkvetch (Astragalus sinicus), black Locust, Chinese milkvetch, mandarin orange (Citrus reticulata), linden (Tilia miqueliana), lychee (Litchi chinensis), longan (Dimocarpus longan), red stringybark (Eucalyptus macrorhyncha), yellow-top mallee ash (Eucalyptus luehmanniana), grey box (Eucalyptus microcarpa), river red gum (Eucalyptus camaldulensis), sweet orange (Citrus sinensis), and yellow box (Eucalyptus melliodora). Compared with PCA and DFA, the least squares support vector machine (LS-SVM), which could retain the non-linear information of the e-nose, had better ability to discriminate both geographical and botanical origins with the overall accuracy of $100 \%$.

An e-nose was used by Pei et al. (2015) for identification of acacia and Jing honey adulteration with rice syrup or rape honey at the level up to $70 \%$. The minimum amount of rape honey and rice syrup added as adulterant to change the aroma of tested honeys was 2 and $1 \%$, respectively. The pure honey and adulterated honey could be well distinguished by LDA, and the accuracy of the discriminant model was $94.7 \%$.

Gan et al. (2016) compared sensor (ultra-fast GC e-nose and e-tongue based on seven potentiometric sensors) and spectroscopic (FT-NIR and FT-IR) techniques for classification of honeys according to the botanical origin (vitex, jujube, acacia) and for determination of rice and corn syrups used as adulterants at the level of $5,10,20$, and $40 \%$. PLS discriminant analysis (PLS-DA), SVM, and interval PLS models were used to classify the botanical origin, whereas PCA and PLS were used to determine the adulterants. They found that the botanical origin of honey could be determined by all tested techniques. Total accuracy for calibration and prediction sets was almost $100 \%$ in e-nose and e-tongue analyses by SVM, and in FTNIR and FT-IR analysis by the interval PLS model. However, FT-NIR and FT-IR spectra were better to confirm the origin of honey than sensors due to higher accuracy. The results also indicated that e-tongue was more suitable for detecting honey adulteration using the PLS model although total accuracy for calibration and prediction sets was above $96 \%$ for all 
techniques. Although ultra-fast GC e-nose was not the best in the classification of honeys according to the botanical origin and in detection of adulterants, its accuracy was high enough to use it for these purposes. This type of e-nose is based on volatile compound separation using an ultra-fast/flash GC chromatograph. Each sample and each recorded chromatographic peak/volatile compound (regarded as sensor) are used to create a matrix of results subsequently analysed by chemometric methods. Before chemometric analysis, preselection of peaks can be done to choose the most efficient ones in differentiation of the tested sample. It cannot be excluded that with a slightly different selection of peaks used for the multivariate analysis, better classification of honeys and more precise detection of adulterants could be obtained using the e-nose than other methods applied in this study.

\section{Alcoholic Beverages}

Discrimination or classification of wines is a rather difficult task, but several attempts have been undertaken to apply enoses of various configurations for this purpose. It is especially important for wines labelled with PGI or PDO symbols to protect their quality, control the wine processing, and prevent the adulteration (Versari et al. 2014).

Italian wines adulterated with methanol and ethanol at the concentration up to $10 \mathrm{vol} . \%$ as well as with other wines of the same colour as the tested wine were recognized using a multisensor array based on four thin-film semiconducting MOX sensors combined with a pattern recognition system of an ANN (Penza and Cassano 2004). It was found that the cross-validated ANN provided correct classifications of 70 , 83.3, and $93.3 \%$ for wines adulterated with ethanol, others with the same-colour wine or methanol, respectively. Good correlation coefficients for predicted versus true concentration of methanol (0.987-0.997) and ethanol (0.902-0.921) adulterant, depending on the type of wine, were also obtained. It indicates that the recognition of wine adulteration using a multisensory array as an analytical tool is possible.

Martí et al. (2004) developed and successfully applied a HS-MS-based e-nose in combination with PCA and SIMCA for the differentiation and classification of wines. Three different studies have been carried out to differentiate and classify wines according to (1) origin, (2) variety, and (3) ageing. Suitable representative samples were chosen: (1) wines from Priorat and Terra Alta (25 in total, most of them were blends of two varieties); (2) 82 Cabernet sauvignon, 66 Tempranillo, and 61 Merlot wines from different Catalonian wine growing zones and 1999-2001 vintages; and (3) 121 wines from Ribera del Duero. Ribera del Duero is a very important wine growing Spanish zone. By a regulatory council, the commercial wines from this zone are classified according to their ageing process into four different administrative categories: Young, Crianza, Reserva, and Gran Reserva wines. The proposed method was simple and fast (10 min per sample). For differentiation of wine origin, only five fragment ions were used as independent variables. Two first principal components explained $97.7 \%$ of the total variability of samples, and the interclass distance between Priorat and Terra Alta wines by applying SIMCA classification was 14.5. This result is very promising because the zones studied by Martí et al. (2004) are geographically very close to each other and their wines are blends of the same varieties. Although, the results obtained in different vintages for wines according to the variety were different and a partial overlap among the different varieties in the 2001 vintage was observed, the suitability of the proposed method was confirmed.

Lozano et al. (2007) studied three sampling methods usually used in e-noses to improve discrimination of wines manufactured from different grape varieties mostly denominated as "Vinos de Madrid". They used SHS with dynamic injection, P\&T, and SPME. For pattern recognition, PCA and PNN were used. The highest response of sensors was obtained by the SHS method, but the best discrimination of wines was achieved with P\&T and SPME. The classification performed with PNN (the success rate) was 100, 95.8, and $87.5 \%$ for SPME, P\&T, and SHS, respectively. Authors suggested that e-nose with HS and P\&T could be more suitable for in situ and portable systems whereas SPME could be used in laboratory.

In the same laboratory, four different wines originating from Madrid region (Malvar and Airén white grape varieties, Garnacha and Tempranillo red grape varieties; all harvested in 2003) were differentiated using a purposely designed portable e-nose containing two different micromachined resistive sensor arrays. When the sensor array with polysilicon heater was applied, a good separation of red and white wines was achieved by PCA; white wines were slightly overlapped, but the PNN classification success was $100 \%$. For the sensor array with platinum heater, a slight overlapping of wines in the PCA plot was observed and classification obtained with a PNN was $88 \%$ (Aleixandre et al. 2008). These results indicate that the variety of grape had a significant influence on the aroma of wines; however, additional studies should be performed to confirm the potential of the proposed e-nose to evaluate the type of wine.

Berna et al. (2009) compared the performance of GC-MS with MOX-based e-nose and MS-based e-nose in the analysis of 34 Sauvignon Blanc wines originating from six regions of France, Australia, and New Zealand. Based on GC-MS data, the LDA revealed three distinct classes of wines with different aroma profiles. The first class comprised wines from the South Australia region with high content of ethyl ethanoate and nerol oxide. The Australian wine from Victoria and the New Zealand ones from the Marlborough region were grouped together due to the similar content of 1-hexanol and trans-2hexenyl butanoate. Wines from the Loire region in France 
and Australian wines from Tasmania and Western Australia created one class. They showed high levels of pentyl ethanoate, hex-4-enoic acid ethyl ester, and propyl decanoate. The usage of SPME with ethanol removal prior to MOS-based e-nose analysis resulted in an average error of prediction of the regional origin of Sauvignon Blanc wines of $6.5 \%$ compared to $24 \%$ when SHS was applied. The misclassification rate for MS-based e-nose was higher (21.4\%) than for MOS-based enose with SPME, but probably the delimitation of the $\mathrm{m} / z$ range considered could improve classification.

The ability of the MS-based e-nose to classify wines according to the geographical origin was confirmed by Cynkar et al. (2010). Differentiation of Tempranillo wines produced in Australia (35 samples) and Spain (25 samples) over six vintages (1999-2004) was possible using PCA. Analysis of the MS-based e-nose data with the use of PLS-DA and Step-LDA with full cross-validation resulted in 85 and $86 \%$ correct classifications of Tempranillo wines according to their geographical origin, respectively.

An e-nose based on the chromatographic principle was used by Antoce and Namolosanu (2011) to analyse the volatile profile of various samples of red wine. They used the ultrafast GC e-nose based on chromatographic peaks of wine volatile compounds and DFA. It was possible to discriminate tested wines according to the geographical origin, grapevine variety or blends, and fraud attempts such as the dilution with water at the level of $10 \%$. The DFA allowed to recognize the $10 \%$ in the blending proportions.

The Tongshan kaoliang spirit is a traditional alcoholic beverage from China, produced in Tongshan town. The most common fraudulent practice concerning this product is the production and selling of the spirit originating from other regions of China. Peng et al. (2015) used the ultra-fast GC enose combined with PCA and DFA for discrimination of the Chinese Tongshan kaoliang spirit of different origin. Three groups of products were used: samples of original Tongshan kaoliang spirit, not Tongshan kaoliang spirit, and blended adulterated spirit. The models developed by PCA and DFA allowed correct classification of tested samples with a prediction rate of $93 \%$. These results are promising and indicate that this type of e-nose could be used as a fingerprinting technique for confirmation of authenticity and protection of the fame of the Chinese Tongshan kaoliang spirit. However, further studies concerning the identification of factors or compounds responsible for differentiation of these products from adulterated counterparts would be valuable.

An e-nose based on the ultra-fast GC was used in the study of Wiśniewska et al. (2016) for differentiation of agricultural distillates (from rye, triticale, wheat, and maize) according to their botanical origin. Agricultural distillates are used for the production of spirit beverages. A specific botanical origin of products is more and more specified on the label (e.g. rye vodkas, wheat vodkas, and Polish Vodka, which cannot be produced with the addition of maize distillate); thus, it is important to have a quick and accurate method allowing confirmation of the botanical origin of these products. PCA, DFA, SIMCA, and statistical quality control (SQC) were used for data analysis. From these methods, DFA and SIMCA allowed full differentiation between the tested distillates. In PCA, two points belonging to one sample of a wheat distillate overlapped with a group of points belonging to distillates produced from triticale (a hybrid of wheat and rye). The SQC analysis only allowed differentiation of rye distillates from other tested distillates. The results of this study confirmed the usefulness of e-nose based on ultra-fast GC for quick confirmation of authenticity of agricultural distillates.

The authors from the same group successfully used the same e-nose (based on fast GC) in combination with the same chemometric methods (PCA, DFA, SIMCA, SQC) for differentiation of three types of cherry liqueurs (Polish home-made liqueurs called nalewka, commercially available liqueurs labelled as nalewka, and commercial liqueurs) (Śliwińska et al. 2016a). Moreover, headspace solid-phase microextraction/ two-dimensional gas chromatography-time-of-flight mass spectrometry (HS-SPME/GCxGC-TOFMS) was used to identify and tentatively semiqualitativaly compare the amount of selected compounds of the volatile fraction of these beverages. It was found that only DFA allowed full discrimination of all groups of samples, whereas PCA, SIMCA, and SQC allowed distinguishing only homemade nalewka and commercial nalewka, but not commercial liqueurs. It was explained by the minor differences in the aroma profiles of commercial products confirmed by HS-SPME/GC $\times$ GC-TOFMS analysis. The results of both studies (Wiśniewska et al. 2016; Śliwińska et al. 2016a) confirmed the usefulness of e-nose based on ultra-fast GC for quick confirmation of the authenticity of agricultural distillates and a Polish traditional product named nalewka.

\section{Other Food Products}

The study on authenticity confirmation of Valencia orange juices of different origins (Israel, Spain, Belize, Florida, and Cuba) based on their aroma had been conducted by Steine et al. (2001). An e-nose based on 12 MOX sensor arrays was applied. PCA and FDA allowed separation of tested samples into five groups according to their origin. The model was developed and used to recognize unknown samples of juice. A percentage of recognition was $93.44-100 \%$ indicating that there is a real potential of the e-nose for the differentiation of pure orange juices according to the origin of the oranges used in the juice production.

Cocchi et al. (2007) proposed an analytical methodology based on HS-MS for recognizing aged and hence marketable samples of the most important Italian traditional balsamic vinegar, "Aceto Balsamico Tradizionale di Modena", from the 
samples which are still undergoing maturation. The obtained instrumental data were first analysed by parallel factor (PARAFAC) analysis (three-way data set: samples $\times$ HS-MS signals $\times$ producers). The results of PARAFAC analysis were then used for a reasonable class subdivision with respect to ageing for further classification analysis performed by LDA and SIMCA. It was found that classification models obtained by LDA and SIMCA could be significantly improved after feature selection by application of the Wavelet Packet Transform for Efficient pattern Recognition (WPTER) algorithm. The SIMCA model showed higher sensitivity but lower specificity for the older samples with respect to classification analysis obtained using the whole set of fragmentation ions. For younger samples, both sensitivity and specificity were improved. The results of LDA were better than SIMCA — only one sample from both types of products was misclassified. Considering the complexity of this food matrix, the obtained results are promising and HS-MS based e-nose could be used for quality control and authenticity assessment of such kind of food.

Hong et al. (2014) with success used MOS based e-nose as well as PCA and CA to recognize adulteration of home-made cherry tomato juices. Overripe tomato juice at the level of 10 , 20 , and $30 \%$ was used as an adulterant. Moreover, an e-tongue and three types of fusion of e-nose and e-tongue datasets were an alternative approaches. Feature selection for fusion datasets were performed by simple sensor concatenation of e-nose and e-tongue, analysis of variance (ANOVA), and stepwise selection. The quality parameters of juices such as $\mathrm{pH}$ and soluble solid contents were also measured, and four regression methods (PCR based on stepwise selection, MLR based on raw feature vector, forward selection and stepwise selection features) were used for quantitative calibration. It was found that the fusion dataset consisting of variables selected by ANOVA presented the best authentication ability. All four regression models presented good quantitative performance with respect to $\mathrm{pH}$ and soluble solid contents. This study also demonstrated that different sensor fusion approaches and statistical methods should be considered to obtain the best results.

Tea quality is very often related to its geographical origin. It is especially important in the case of middle- and premiumquality tea products, because the origin is usually displayed on the label and it plays an important role in the consumers' choice. Three most important tea growing countries are India, China, and Sri Lanka. In Sri Lanka, the tea quality is classified not only according to the plantation locations but also according to growing altitude (Kovács et al. 2010). Five black teas originating from Sri Lanka were examined by Kovács et al. (2010) using an e-nose based on 22 metal oxide semiconductor field-effect transistors (MOSFETs) and MOS sensors, potentiometric e-tongue, and sensory assessment. The tea growing regions were Kandy (the tea plantations located between 650 and $1300 \mathrm{~m}$ ), Uva located 1200-1500 m, Dimbula located at 1200-1700 m, Nuwara Eliya located at
$2000 \mathrm{~m}$, and Ruhuna at $600 \mathrm{~m}$. E-nose and e-tongue data were analysed with PCA and LDA. In the case of sensory analysis, one-way ANOVA was used. PLS was used to develop models for predicting sensory values of black tea samples by e-nose and e-tongue data. Taking into account the data from e-nose, the results of PCA revealed that only Kandy and Ruhuna tea samples could be separated from other ones. LDA was able to differentiate Dimbula, Kandy, and Ruhuna teas, whereas Nuwara Eliya and Uva samples were overlapped. Results of cross-validation of the confusion matrix showed that $100 \%$ of Dimbula, Kandy, and Ruhuna samples were correctly classified; the correct classification in the case of Nuvara Eliya was only $37.5 \%$, and that of Uva was $75 \%$. Based on the results of LDA, it was also concluded that e-nose seems to be a good tool for the discrimination of tea samples according to elevation of the growing region, because "high-grown" tea types (Dimbula, Nuwara Eliya, and Uva), "medium-grown" tea types represented by Kandy, and "low-grown" tea types by Ruhuna were distinguished. In contrast to e-nose, e-tongue was suitable for the qualitative discrimination of five black tea types (100\% prediction for all tea types). Using the PLS method, the correlation between the e-nose/e-tongue data and the sensory panel scores was also found. The results of this study showed that a larger data set should be used for the development of a more robust and reliable model based on e-nose data to recognize tea according to growing regions.

Adulteration of coffee may be related e.g. to the replacement of a cheaper Robusta variety with an Arabica one or mixing Arabica with Robusta beans. In the study of Buratti et al. (2015), FT-NIR (for green and roasted coffee), e-nose with 10 MOS sensors (for roasted coffee), and e-tongue (for roasted coffee infusions) were applied to discriminate natural Arabica, washed Arabica, and natural Robusta varieties. PCA and LDA were applied to FT-NIR, e-nose, and e-tongue data sets in order to classify coffee samples into three groups (washed Arabica, natural Arabica, and Robusta). The LDA classification models were characterized by the percentage of correctly classified samples in calibration and in cross-validation. The average values of correctly classified samples in cross-validation were $100,81.83$, and $78.76 \%$ for FT-NIR, e-nose and e-tongue, respectively. Robusta coffees were better classified than natural and washed Arabica samples: a recognition of $100 \%$ in calibration and in cross-validation was obtained for both e-nose and e-tongue. Although FT-NIR spectroscopy was the best technique to discriminate tested samples, the obtained results for e-nose were also promising. Using PCA, the differentiation between washed and natural Arabica was not possible, while a clear separation of Robusta from Arabica samples was obtained. It cannot be excluded that application of other chemometric methods could improve classification of coffee samples.

Spices are very often the subject of adulteration. Banach et al. (2012) demonstrated application of e-nose based on doped 
tin oxide and ion mobility spectrometry, supported by LDA and PCA, for detection of adulteration in spice mixtures (for "saveloy" and "sausages" adulterated with $20 \%$ of curry spice or $20 \%$ of garlic powder, respectively). Moreover, the analysis of volatile compounds from spices was performed by GC-MS to identify the main compounds which are responsible for their aroma. It was found that both gas sensors permitted discrimination between the type of spice mixture and adulterated ones. The adulteration can be also distinguished by the MS spectra, but the identification of the type of adulteration was difficult. However, the addition of curry containing black pepper to saveloy mixture was indicated by the presence of 3-carene, whereas the addition of garlic to sausage mixture indicated by the presence of $\gamma$-terpinene. The typical natural, volatile ingredient of garlic, alliin, was not observable by GC-MS.

Saffron is the commercial name of the dried stigmas of the Crocus sativus L. flower. It is used as a food additive due to its colour, aroma, and bitter taste and is also used in traditional medicine (Singh et al. 2010; Campo et al. 2009; Kianbakht and Mozaffari 2009). Saffron is very expensive; thus, adulteration sometimes occurs (Heidarbeigi et al. 2015). The aroma of saffron and saffron adulterated with safflower, yellow styles, and dyed corn stigma coloured with beetroot dye were evaluated using an e-nose based on six MOS sensors by Heidarbeigi et al. (2015). PCA was used to visualize the saffron adulteration, and the results were confirmed by ANN. It was found that the e-nose combined with ANN can classify saffron and saffron with adulterating materials. Classification accuracy of $86.87 \%$ was obtained for saffron and its mixtures with yellow style and dyed corn stigma; for saffron and safflower, the classification accuracy was $100 \%$. The e-nose successfully differentiated non-adulterated and adulterated saffron at the adulteration level of at least $10 \%$.

\section{Sensor- and MS-Based e-Noses Used for Food Authenticity Confirmation}

Various e-nose systems have been used in the area of food authenticity confirmation (Table 1). Their principles of operation are clearly explained in review articles by, e.g. Dymerski et al. (2011) and Śliwińska et al. (2014).

The most frequently used e-noses are those based on conductometric sensors. They measure resistance changes under the influence of volatile compounds and include MOS, MOSFET, and conductive polymers (CP). They can be divided into "hot" and "cold" sensors. Hot sensors can operate at higher temperatures. Their susceptibility to humidity is low, but their applications are limited. The MOS sensors are the most popular sensors used in commercially available e-noses because they are stable in time, sensitive, relatively inexpensive, and easy to operate. The MOSFET sensors are inexpensive and small, but their main disadvantages are drifting baseline and low sensitivity to carbon dioxide and ammonia. The $\mathrm{CP}$ sensor advantages are fast response and low price, but the main disadvantage is susceptibility to humidity (Dymerski et al. 2011; Śliwińska et al. 2014). Actually, most of the applications listed in Table 1 were studied using e-noses based on MOS. E-noses based on conductometric sensors have been used for geographical origin confirmation or adulteration detection of dairy products (Cevoli et al. 2011; Pillonel et al. 2003; Yu et al. 2007), plant oils (Bougrini et al. 2014; Cerrato Oliveros et al. 2002; Cosio et al. 2006; Guadarrama et al. 2001; Haddi et al. 2011; Hai and Wang 2006; Mildner-Szkudlarz and Jeleń 2008, Mildner-Szkudlarz and Jelen 2010; Wei et al. 2015), meat and meat products (Laureati et al. 2014; Tian et al. 2013), honey (Huang et al. 2015; Pei et al. 2015; Subari et al. 2012; Subari et al. 2014; Zakaria et al. 2011), beverages (Aleixandre et al. 2008; Berna et al. 2009; Hong et al. 2014; Lozano et al. 2007; Penza and Cassano 2004; Steine et al. 2001), coffee (Buratti et al. 2015), tea (Kovács et al. 2010), and some spices (Banach et al. 2012; Heidarbeigi et al. 2015).

Commercially available $\mathrm{zNose} \mathrm{TM}^{\mathrm{TM}}$ is a surface acoustic wave (SAW) device. It was used to detect adulteration of palm olein (Che Man et al. 2005), virgin coconut oil (Marina et al. 2010), lard (Nurjuliana et al. 2011a), and meat (Nurjuliana et al. 2011b). The SAW is a piezoelectric sensor measuring the resonant frequency of the sensor, which is changed due to the changes in the mass caused by the adsorption or absorption of volatile compounds. The advantages of SAW sensors are the relatively short response time and high selectivity, but their sensitivity is rather low and depends on the type of sensor polymer coating. They are also sensitive to the changes of temperature and humidity, and their production technology is characterized by poor reproducibility (Dymerski et al. 2011).

The MS-based e-noses are less popular than sensor-based systems because of their high cost. However, they have unquestionable advantages over other instruments. They include a wider range of applications by using appropriate conditions of analysis to obtain the optimal ion fragmentation pattern, higher sensitivity due to the possibility to reject ions originating from potentially interfering components, such as ethanol or water, and shorter response time. Moreover, MS spectra provide chemical information about the sample, therefore differentiation of different samples is possible (Peris and Escuder-Gilabert 2009). In the area of food authenticity, MS-based e-noses have been used to confirm the geographical origin of cheese (Pillonel et al. 2002; Majcher et al. 2015), olive oils (Cerrato Oliveros et al. 2005), and wine (Cynkar et al. 2010; Martí et al. 2004), authenticity of traditional vinegar (Cocchi et al. 2007), olive oil adulteration (Lorenzo et al. 2002; Peña et al. 2005), and botanical origin of honey (Ampuero et al. 2004).

E-noses based on volatile compound separation using ultra-fast GC take the advantages of GC and a sensor-based e-nose. It is possible to obtain information on both volatile composition of investigated samples and volatile fraction 
profile during a single analysis. Therefore, complete information on similarity of a sample to the reference sample/pattern (reference database) is obtained. The ultra-fast GC-based enoses are more suitable for applications in which chemical information about specific volatile compounds is needed or the analysis is focused on aroma compounds. They require also better analytical skills to interpret chromatographic data (Müller von Blumencron et al. 2015). Ultra-fast GC-based enoses have been used for authenticity confirmation of some alcoholic beverages (Antoce and Namolosanu 2011; Peng et al. 2015; Śliwińska et al. 2016a; Wiśniewska et al. 2016).

The choice of the method for e-nose data analysis depends on the obtained data and what is expected: pattern analysis or qualitative analysis. Many multivariate analysis methods can be employed. The most frequently used are PCA, LDA, and DFA as classification methods, whereas PLS is used to construct predicting models for qualitative analysis of adulterant (Table 1). The review of various data analysis methods can be found in the literature, e.g. in Dymerski et al. (2011) and Śliwińska et al. (2014).

\section{Conclusions}

Application of e-noses in the field of food and agricultural sciences includes quality control, monitoring technological process, ageing, spoilage, and others. In the last years, several studies were carried out to use an e-nose in the area of food authenticity including adulteration and origin confirmation. The results of these studies indicate that it is possible to detect any adulteration practice or confirm the origin of various products having the characteristic fingerprint aroma. Using different classification methods, no less than $80 \%$ or, in many cases, even $100 \%$ of correct classification can be obtained depending on product and e-nose system. In some studies, it was pointed out that the classification capability of e-noses can be even better than that obtained by GCMS. In quantitative analyses with the use of e-noses, the presence of adulterant in some products can be detected at the level of $1 \%$. Therefore, the results of the studies discussed in this paper indicate that there is a real potential of e-noses in the field of food authentication. Most of the e-noses give information about the characteristic odour of the product or its changes upon addition of adulterant without separation of volatile compounds. An e-nose based on ultra-fast GC gives the possibility to obtain the information not only on aroma of the product but also on volatile composition of tested samples. This type of instrument requires the experience in GC data interpretation; thus, the choice between sensor- and GC-based e-noses depends on the purpose of the analysis and the skills of the operator.

Altogether, the e-noses of various configurations are nondestructive tools, which combined with chemometric methods became rapid and sensitive techniques for monitoring the authenticity of food.
ANN, artificial neural network; BPNN, back propagation neural network; $\mathrm{CA}$, cluster analysis; $\mathrm{CP}$, conductive polymer; CP-ANN, counter-propagation artificial neural network; DFA, discriminant function analysis; EMA, economically motivated adulteration; E-nose, electronic nose; FAD, Food and Drug Administration; FLT, Fisher linear transformation; FT-IR, Fourier transform infrared spectroscopy; GC, gas chromatography; GC-FID, gas chromatography with flame ionization detector; GRNN, general regression neural network; HS, headspace; HS-SPME/GC $\times$ GC-TOFMS, headspace solid-phase microextraction/two-dimensional gas chromatography-time-of-flight mass spectrometry; HS-MS, headspace coupled with mass spectrometer; INDEX, inside-needle dynamic extraction; LDA, linear discriminant analysis; LSSVM, least squares support vector machine; MLR, multiple linear regression; MOS, metal oxide semiconductor; MOSFET, metal oxide semiconductor field-effect transistor; MOX, metal oxide; MS, mass spectrometer; P\&T, purge-andtrap technique; PARAFAC, parallel factor; PCA, principal component analysis; PCR, principal component regression; PDO, Protected Designation of Origin; PGI, Protected Geographical Indication; PLS, partial least squares; PLSDA, partial least squares discriminant analysis; PNN, probabilistic neural networks; QDA, quadratic discriminant analysis; RMSE, root mean square error; SAW, surface acoustic wave; SFW, selection by Fisher weights; SHS, static headspace; SIMCA, soft independent modelling of class analogy; SPME, solid phase microextraction; SPME-MS, solid phase microextraction coupled with mass spectrometry; SQC, statistical quality control; Step-LDA, stepwise linear discriminant analysis; SVM, support vector machine; TSG, Traditional Speciality Guaranteed; WPTER, wavelet packet transform for efficient pattern recognition.

\section{Compliance with Ethical Standards}

Funding Not applicable.

Conflict of Interest Anna Gliszczyńska-Świgło declares that she has no conflict of interest. Jarosław Chmielewski declares that he has no conflict of interest.

Ethical Approval This article does not contain any studies with human participants or animals performed by any of the authors.

Informed Consent Not applicable.

Open Access This article is distributed under the terms of the Creative Commons Attribution 4.0 International License (http:// creativecommons.org/licenses/by/4.0/), which permits unrestricted use, distribution, and reproduction in any medium, provided you give appropriate credit to the original author(s) and the source, provide a link to the Creative Commons license, and indicate if changes were made. 


\section{References}

Aleixandre M, Lozano J, Gutiérrez J, Sayago I, Fernández MJ, Horrillo MC (2008) Portable e-nose to classify different kinds of wine. Sensor Actuat B-Chem 131:71-76

Ampuero S, Bogdanov S, Bosset JO (2004) Classification of unifloral honeys with an MS-based electronic nose using different sampling modes: SHS, SPME and INDEX. Eur Food Res Technol 218:198207

Antoce AO, Namolosanu I (2011) Rapid and precise discrimination of wines by means of an electronic nose based on gas-chromatography. Revistade Chimie (Bucarest) 62:593-595

Asensio L, González I, García T, Martin R (2008) Determination of food authenticity by enzyme-linked immunosorbent assay (ELISA). Food Contr 19:1-8

Banach U, Tiebe C, Hübert T (2012) Multigas sensors for the quality control of spice mixtures. Food Contr 26:23-27

Berna A (2010) Metal oxide sensors for electronic noses and their application to food analysis. Sensors 10:3882-3910

Berna AZ, Trowell S, Clifford D, Cynkar W, Cozzolino D (2009) Geographical origin of Sauvignon Blanc wines predicted by mass spectrometry and metal oxide based electronic nose. Anal Chim Acta 648:146-152

Bougrini M, Tahri K, Haddi Z, Saidi T, El Bari N, Bouchikhi B (2014) Detection of adulteration in argan oil by using an electronic nose and a voltammetric electronic tongue. J Sens 2014:1-10

Buratti S, Sinelli N, Bertone E, Venturello A, Casiraghi E, Geobaldo F (2015) Discrimination between washed Arabica, natural Arabica and Robusta coffees by using near infrared spectroscopy, electronic nose and electronic tongue analysis. J Sci Food Agric 95:2192-2200

Campo PC, Garde-Cerdan T, Sanchez AM, Maggi L, Carmona M, Gonzalo LA (2009) Determination of free amino acids and ammonium ion in saffron (Crocus sativus L.) from different geographical origins. Food Chem 114:1542-1548

Cerrato Oliveros MC, Pérez Pavón JL, Garcia Pinto C, Fernández Laespada ME, Moreno Cordero B, Forina M (2002) Electronic nose based on metal oxide semiconductor sensors as a fast alternative for the detection of adulteration of virgin olive oils. Anal Chim Acta 459:219-228

Cerrato Oliveros C, Boggia R, Casale M, Armanino C, Forina M (2005) Optimisation of a new headspace mass spectrometry instrument. Discrimination of different geographical origin olive oils. J Chromatogr A 1076:7-15

Cevoli C, Cerretani L, Gori A, Caboni MF, Gallina Toschi T, Fabbri A (2011) Classification of Pecorino cheeses using electronic nose combined with artificial neural network and comparison with GCMS analysis of volatile compounds. Food Chem 129:1315-1319

Che Man YB, Gan HL, NorAini I, Nazimah SAH, Tan CP (2005) Detection of lard adulteration in RBD palm olein using an electronic nose. Food Chem 90:829-835

Chen S-Y, Liu Y-P, Yao Y-G (2010) Species authentication of commercial beef jerky based on PCR-RFLP analysis of the mitochondrial $12 \mathrm{~S}$ rRNA gene. J Genet Genomics 37:763-769

Chou CC, Lin SP, Lee KM, Hsu CT, Vickroy TW, Zen JM (2007) Fast differentiation of meats from fifteen animal species by liquid chromatography with electrochemical detection using copper nanoparticle plated electrodes. J Chromatogr B 846:230-239

Cocchi M, Durante C, Marchetti A, Armanino C, Casale M (2007) Characterization and discrimination of different aged 'Aceto Balsamico Tradizionale di Modena' products by head space mass spectrometry and chemometrics. Anal Chim Acta 589:96-104

Coppa M, Martin B, Agabriel C, Chassaing C, Sibra C, Constant I, Graulet B, Andueza D (2012) Authentication of cow feeding and geographic origin of milk using visible and near-infrared spectroscopy. J Dairy Sci 95:5544-5551

Cosio MS, Ballabio D, Benedetti S, Gigliotti C (2006) Geographical origin and authentication of extra virgin olive oils by an electronic nose in combination with artificial neural networks. Anal Chim Acta 567:202-210

Cozzolino D, Murray I (2004) Identification of animal meat muscles by visible and near infrared reflectance spectroscopy. LWT-Food Sci Technol 37:447-452

Cynkar W, Dambergs R, Smith P, Cozzolino D (2010) Classification of Tempranillo wines according to geographic origin: combination of mass spectrometry based electronic nose and chemometrics. Anal Chim Acta 660:227-231

Dymerski TM, Chmiel TM, Wardencki W (2011) Invited review article: an odor-sensing system - powerful technique for foodstuff studies. Rev Sci Instrum 82:111101-111132

Gan Z, Yang Y, Li J, Wen X, Zhu M, Jiang Y, Ni Y (2016) Using sensor and spectral analysis to classify botanical origin and determine adulteration of raw honey. J Food Eng 178:151-158

Ghovvati S, Nassiri MR, Mirhoseini S, Moussavi AH, Javadmanesh A (2009) Fraud identification in industrial meat products by multiplex PCR assay. Food Contr 20:696-699

Guadarrama A, Rodriguez-Mendez ML, Sanz C, Rios JL, de Saja JA (2001) Electronic nose based on conducting polymers for the quality control of the olive oil aroma. Discrimination of quality, variety of olive and geographic origin. Anal Chim Acta 432:283-292

Haddi Z, Amari A, Ould Ali A, El Bari N, Barhoumi H, Maaref A, Jaffrezic-Renault N, Bouchikhi B (2011) Discrimination and identification of geographical origin virgin olive oil by an e-nose based on MOS sensors and pattern recognition techniques. Procedia Eng 25: $1137-1140$

Hai Z, Wang J (2006) Electronic nose and data analysis for detection of maize oil adulteration in sesame oil. Sensor Actuat B-Chem 119: $449-455$

Heidarbeigi K, Mohtasebi SS, Foroughirad A, Ghasemi-Varnamkhasti M, Rafiee S, Rezaei K (2015) Detection of adulteration in saffron samples using electronic nose. International J Food Propert 8:13911401

Hong X, Wang J, Qiu S (2014) Authenticating cherry tomato juicesdiscussion of different data standardization and fusion approaches based on electronic nose and tongue. Food Res Int 60:173-179

Hrbek V, Vaclavik L, Elich O, Hajslova J (2014) Authentication of milk and milk-based foods by direct analysis in real time ionization-high resolution mass spectrometry (DART-HRMS) technique: a critical assessment. Food Contr 36:138-145

Huang L, Liu H, Zhang B, Wu D (2015) Application of electronic nose with multivariate analysis and sensor selection for botanical origin identification and quality determination of honey. Food Bioprocess Tech 8:359-370

Kamal M, Karoui R (2015) Analytical methods coupled with chemometric tools for determining the authenticity and detecting the adulteration of dairy products: a review. Trends Food Sci Technol 46:27-48

Kianbakht S, Mozaffari K (2009) Effects of saffron and its active constituents, Crocin and Safranal, on prevention of indomethacin induced gastric ulcers in diabetic and non-diabetic rats. J Med Plants 8:30-38

Kovács Z, Dalmadi I, Lukács L, Sipos L, Szántai-Kőhegyi K, Kókai Z, Fekete A (2010) Geographical origin identification of pure Sri Lanka tea infusions with electronic nose, electronic tongue and sensory profile analysis. J Chemometrics 24:121-130

Krist S, Stuebiger G, Bail S, Unterweger H (2006) Detection of adulteration of poppy seed oil with sunflower oil based on volatiles and triacylglycerol composition. J Agric Food Chem 54:6385-6389

Laureati M, Buratti S, Giovanelli G, Corazzin M, Lo Fiego DP, Pagliarini E (2014) Characterization and differentiation of Italian Parma, San Daniele and Toscano dry-cured hams: a multi-disciplinary approach. Meat Sci 96:288-294 
Liu M, Han X, Tu K, Pan L, Tu J, Tang L, Liu P, Zhan G, Zhong Q, Xiong Z (2012) Application of electronic nose in Chinese spirits quality control and flavour assessment. Food Contr 26:564-570

Lohumi S, Lee S, Lee H, Cho B-K (2015) A review of vibrational spectroscopic techniques for the detection of food authenticity and adulteration. Trends Food Sci Technol 46:85-98

López-Díez EC, Bianchi G, Goodacre R (2003) Rapid quantitative assessment of the adulteration of virgin olive oils with hazelnut oils using Raman spectroscopy and chemometrics. J Agric Food Chem 51:6145-6150

Lorenzo IM, Pavon JLP, Laespada MEF, Pinto CG, Cordero BM (2002) Detection of adulterants in olive oil by headspace-mass spectrometry. J Chromatogr A 945:221-230

Loutfi A, Coradeschi S, Mani GK, Shankar P, Rayappan JBB (2015) Electronic noses for food quality: a review. J Food Eng 144:103-111

Lozano J, Santos JP, Gutiérrez J, Horrillo MC (2007) Comparative study of sampling systems combined with gas sensors for wine discrimination. Sensor Actuat B-Chem 126:616-623

Lv S-D, Wu Y-S, Song Y-Z, Zhou J-S, Lian M, Wang C, Liu L, Meng QX (2014) Multivariate analysis based on GC-MS fingerprint and volatile composition for the quality evaluation of Pu-Erh green tea. Food Anal Methods 7:1840-1847

Majcher M, Ławrowski P, Jeleń H (2010) Comparison of original and adulterated Oscypek cheese based on volatile and sensory profiles. Acta Sci Pol Technol Aliment 9:265-275

Majcher MA, Kaczmarek A, Klensporf-Pawlik D, Pikul J, Jeleń HH (2015) SPME-MS-based electronic nose as a tool for determination of authenticity of PDO cheese, Oscypek. Food Anal Methods 8: 2211-2217

Marikkar JMN, Lai OM, Ghazali HM, Che Man YB (2002) Compositional and thermal analysis of RBD palm oil adulterated with lipase-catalyzed interesterified lard. Food Chem 76:249-258

Marina AM, Che Man YB, Amin I (2010) Use of the SAW sensor electronic nose for detecting the adulteration of virgin coconut oil with RBD palm kernel olein. J Am Oil Chem Soc 87:263-270

Martí MP, Busto O, Guasch J (2004) Application of a headspace mass spectrometry system to the differentiation and classification of wines according to their origin, variety and ageing. J Chromatogr A 1057: 211-217

Meza-Marquez OG, Gallardo-Velazquez T, Osorio-Revilla G (2010) Application of mid-infrared spectroscopy with multivariate analysis and soft independent modeling of class analogies (SIMCA) for the detection of adulterants in minced beef. Meat Sci 86:511-519

Mildner-Szkudlarz S, Jeleń HH (2008) The potential of different techniques for volatile compounds analysis coupled with PCA for the detection of the adulteration of olive oil with hazelnut oil. Food Chem 110:751-761

Mildner-Szkudlarz S, Jeleń H (2010) Detection of olive oil adulteration with rapeseed and sunflower oils using MOS electronic nose and SPME-MS. J Food Qual 33:21-41

Mohammed FAE, Bchitou R, Bouhaouss A, Gharby S, Harhar H, Guillaume D, Charrouf Z (2013) Can the dietary element content of virgin argan oils really be used for adulteration detection? Food Chem 136:105-108

Moore JC, Spink J, Lipp M (2012) Development and application of a database of food ingredient fraud and economically motivated adulteration from 1980 to 2010. J Food Sci 77:R118-R126

Müller von Blumencron M, Hamacher E, Schneider-Häder B, Wiech H, Wortelmann T (2015) Instrumental sensory analysis in the food industry. Part 1: electronic noses. DLG-Expert report 2:2-8

Nurjuliana M, Che Man YB, Mat Hashim D (2011a) Analysis of lard's aroma by an electronic nose for rapid halal authentication. J Am Oil Chem Soc 88:75-82

Nurjuliana M, Che Man YB, Mat Hashim D, Mohamed AKS (2011b) Rapid identification of pork for halal authentication using the electronic nose and gas chromatography mass spectrometer with headspace analyzer. Meat Sci 88:638-644

Pei G, Shi B, Zhao L, Gao H, Yin J, Wang H, Zhi R (2015) Information variation feature and discriminant capabilities of electronic nose for typical adulteration honey identification. Trans Chinese Soc Agric Eng 31:323-331

Peña F, Càrdenas S, Gallego M, Valcàrcel M (2005) Direct olive oil authentication: detection of adulteration of olive oil with hazelnut oil by direct coupling of headspace and mass spectrometry, and multivariate techniques. J Chromatogr A 1074:215-221

Peng Q, Tian R, Chen F, Li B, Gao H (2015) Discrimination of producing area of Chinese Tongshan kaoliang spirit using electronic nose sensing characteristics combined with the chemometrics methods. Food Chem 178:301-305

Penza M, Cassano G (2004) Recognition of adulteration of Italian wines by thin-film multisensor array and artificial neural networks. Anal Chim Acta 509:159-177

Peris M, Escuder-Gilabert L (2009) A 21st century technique for food control: electronic noses. Anal Chim Acta 638:1-15

Pillonel L, Ampuero S, Tabacchi R, Bosset JO (2003) Analytical methods for the determination of the geographic origin of Emmental cheese: volatile compounds by GC/MS-FID and electronic nose. Eur Food Res Technol 216:179-183

Pizzoni D, Compagnone D, Di Natale C, D’Alessandro N, Pittia P (2015) Evaluation of aroma release of gummy candies added with strawberry flavours by gas-chromatography/mass-spectrometry and gas sensors arrays. J Food Eng 167:77-86

Poulli KI, Mousdis GA, Georgiou CA (2007) Rapid synchronous fluorescence method for virgin olive oil adulteration assessment. Food Chem 105:369-375

Qiu S, Gao L, Wang J (2015) Classification and regression of ELM, LVQ and SVM for E-nose data of strawberry juice. J Food Eng 144:7785

Rapid Alert System for Food and Feed, Annual Report (2012) European Communities, 2012

Reid LM, O'Donnell CP, Downey G (2006) Recent technological advances for the determination of food authenticity. Trends Food Sci Technol 17:344-353

Rohman A, Che Man YB (2012) Analysis of pig derivatives for halal authentication studies. Food Rev Int 28:97-112

Rohman A, Sismindari EY, Che Man YB (2011) Analysis of pork adulteration in beef meatball using Fourier transform infrared (FTIR) spectroscopy. Meat Sci 88:91-95

Salguero-Chaparro L, Baeten V, Fernández-Pierna JA, Peña-Rodríguez F (2013) Near infrared spectroscopy (NIRS) for online determination of quality parameters in intact olives. Food Chem 139:1121-1126

Schaller E, Bosset JO, Esher F (1998) Electronic noses and their application to food. Lebensmit-Wissen Technol 31:305-316

Singh AK, Singh L, Verma N (2010) Extent and pattern of agromorphological diversity in saffron (Crocus sativus L.) from Jammu and Kashmir in India. Progress Agric 10:232-239

Śliwińska M, Wiśniewska P, Dymerski T, Namieśnik J, Wardencki W (2014) Food analysis using artificial senses. J Agric Food Chem 62:1423-1448

Śliwińska M, Wiśniewska P, Dymerski T, Wardencki W, Namieśnik J (2016a) Application of electronic nose based on fast GC for authenticity assessment of Polish homemade liqueurs called nalewka. Food Anal Methods 9:2670-2681

Śliwińska M, Wiśniewska P, Dymerski T, Wardencki W, Namieśnik J (2016b) Advances in electronic noses and tongues for food authenticity testing. In: Downey G (ed) Advances in food authenticity testing, 1st edn. Elsevier, p 201-225

Šmejkalová D, Piccolo A (2010) High-power gradient diffusion NMR spectroscopy for the rapid assessment of extra-virgin olive oil adulteration. Food Chem 118:153-158 
Spink J, Moyer DC (2011) Defining the public health threat of food fraud. J Food Sci 76:R157-R163

Stanimirova I, Ustun B, Cajka T, Riddelova K, Hajslova J, Buydens LMC, Walczak B (2010) Tracing the geographical origin of honeys based on volatile compounds profiles assessment using pattern recognition techniques. Food Chem 118:171-176

Steine C, Beaucousin F, Siv C, Peiffer G (2001) Potential of semiconductor sensor arrays for the origin authentication of pure Valencia orange juices. J Agric Food Chem 49:31513160

Subari N, Saleh JM, Shakaff AYM, Zakaria A (2012) A hybrid sensing approach for pure and adulterated honey classification. Sensors 12: 14022-14040

Subari N, Saleh JM, Shakaff AYM (2014) Fusion technique for honey purity estimation using artificial neural network. WIT Trans Inform Commun Technol 53:61-68

Tian X, Wang J, Cui S (2013) Analysis of pork adulteration in minced mutton using electronic nose of metal oxide sensors. J Food Eng 119:744-749

Tu D, Li H, Wu Z, Zhao B, Li Y (2014) Application of headspace solid phase microextraction and multivariate analysis for the differentiation between edible oils and waste cooking oil. Food Anal Methods 7:1263-1270

Versari A, Laurie VF, Ricci A, Laghi L, Parpinello GP (2014) Progress in authentication, typification and traceability of grapes and wines by chemometric approaches. Food Res Int 60:2-18

Wei CQ, Liu WY, Xi WP, Cao D, Zhang HJ, Ding M, Chen L, Xu YY, Huang KX (2015) Comparison of volatile compounds of hot- pressed, cold-pressed and solvent-extracted flaxseed oils analyzed by SPME-GC/MS combined with electronic nose: major volatiles can be used as markers to distinguish differently processed oils. Eur J Lipid Sci Technol 117:320-330

Wilson AD, Baietto M (2009) Applications and advances in electronicnose technologies. Sensors 9:5099-5148

Wiśniewska P, Śliwińska M, Dymerski T, Wardencki W, Namieśnik J (2016) Differentiation between spirits according to their botanical origin. Food Anal Methods 9:1029-1035

Xiao Z, Yu D, Niu Y, Chen F, Song S, Zhu J, Zhu G (2014) Characterization of aroma compounds of Chinese famous liquors by gas chromatography-mass spectrometry and flash GC electronic-nose. J Chromatogr B Anal Technol Biomed Life Sci 945-946:92-100

Yu H, Wang J, Xu Y (2007) Identification of adulterated milk using electronic nose. Sensor Mater 19:275-285

Zakaria A, Shakaff AY, Masnan MJ, Ahmad MN, Adom AH, Jaafar MN, Ghani SA, Abdullah AH, Aziz AH, Kamarudin LM, Subari N, Fikri NA (2011) A biomimetic sensor for the classification of honeys of different floral origin and the detection of adulteration. Sensors (Basel) 11:7799-7822

Zhang N, Zhang D, Li S, Li Q (2008) Preliminary study on origin traceability of mutton by near infrared reflectance spectroscopy coupled with SIMCA method. Trans Chinese Soc Agric Eng 24:309-312

Zohora SE, Khan AM, Srivastava AK, Hundewale N (2013) Electronic noses application to food analysis using metal oxide sensors: a review. Int J Soft Comput Eng (IJSCE) 3:199-205 